\title{
Serebral palsi ve egzersiz
}

\author{
Cerebral palsy and exercise \\ Ünsal Tazegül1 ${ }^{1}$, Özdemir Atar², Merve Ferah Tazegül ${ }^{1}$ \\ ${ }^{1}$ Iğdır Üniversitesi, Beden Eğitimi ve Spor Yüksekokulu, Iğdır \\ ${ }^{2}$ Çanakkale Onsekiz Mart Üniversitesi, Spor Bilimleri Fakültesi, Antrenörlük Eğitimi Bölümü, Çanakkale
}

\begin{abstract}
Serebral palsi, gelişmekte olan beynin hasarı sonucu oluşan bir rahatsızlıktır. Serebral palsili bireylerde; denge, duruş bozuklukları, iskelet ve kas sistemlerinde bozukluklar, motor kontrollerinde oluşan kayıplar ve kas tonusunda anormallikler görülebilmektedir. Yapılan bu çalışmanın amacı, egzersiz ve sporun serebral palsi üzerindeki etkisini ortaya koymaktır. Konuyla ilgili yapılmış olan çalışmalara göre, egzersiz ve sporun serebral palsi üzerinde olumlu bir etkisi olduğu anlaşılmıştır. Egzersiz ve spor serebral palsili bireylerin psikolojik iyi oluşlarını da olumlu etkilemektedir. Sonuç olarak, egzersiz ve sporun serebral palsili bireylerin yaşamlarını kolaylaştırdığı ve motor kontrolleri üzerinde olumlu etkisi olduğu anlaşılmıştır. Ayrıca sosyal ve psikolojik olarak da olumlu etkileri olduğu görülmüştür.
\end{abstract}

Anahtar sözcülkler: serebral palsi; egzersiz; spor
Cerebral palsy is a condition caused by brain damage. In individuals with cerebral palsy; balance, posture disorders, skeletal and muscular system disorders, loss of motor control and abnormalities in muscle tone can be seen. The purpose of this study was to determine the effect of exercise and sports on cerebral palsy. It has been understood that exercise and sports have a positive effect on cerebral palsy. In addition, according to the results of the studies, exercise and sports positively affect the psychological wellbeing of individuals with cerebral palsy. As a result, it is understood that exercise and sports facilitate the lives of individuals with cerebral palsy and have a positive effect on their motor control. It has also been found to have positive social and psychological effects.

Key words: cerebral palsy; exercise; sports erebral palsi, bireyin gelişiminin ilk evrelerinde, beyinde oluşan lezyonlar sonucunda meydana gelmektedir. Bu lezyonlar sonucunda hasara bağlı gelişen, hareket ve duruş bozukluğu olarak tanımlanmaktadır. ${ }^{[1]}$ Serebral palsi, birçok klinik durumun bir arada görüldüğü bulgular bütünüdür. Klasik tabloda motor işlev bozukluğu ön plandadır. Motor işlev bozuklukları, aynı zamanda birçok santral sinir sistemi kökenli nörolojik bozuklukla birlikte görülebilir. ${ }^{[2,3]}$

Primer (Birincil) eksiklikler; pozisyon, duruş ve hareketten etkilenen kas tonusu anormallikleri, denge ve koordinasyon bozukluğu, azalmış kas gücü ve selektif motor kontrol kaybından oluşur. Sekonder (ikincil) kas-iskelet sistemi problemleri ise, kas kontraktürleri ve kemik deformiteleridir. Bunlar, primer eksikliklere cevap olarak, aşamalı olarak gelişir ve daha fazla motor işlev bozukluğuna yol açar. Yaşanan bu karmaşık sorunlar sebebiyle serebral palsi rehabilitasyonu multidisipliner bir rehabilitasyon ve tedavi yaklaşımı gerektirir. ${ }^{[4]}$ Serebral palsili çocuklarda görülen sorunlar, beyin hasarının oluştuğu yere ve hasarın genişliğine bağlıdır. ${ }^{[5]}$

\section{SEREBRAL PALSILI BIREYLERDE EGZERSIZIN ÖNEMi}

Serebral palsili çocukların yaşlarına uygun eğlence ve spor faaliyetlerinde bulunabilmeleri, ruh ve beden sağlığı açısından önem kazanmaktadır. Rehabilitasyon etkisi olan hipoterapi (ata binme) ve hidroterapi (yüzme) egzersizleri tercih edilebilir. Bunların haricinde serebral palsili bireyler için tekerlekli sandalye (TS) basketbolu, TS tenisi, TS masa tenisi, TS okçuluk ve TS atletizm gibi sporlar yaptırılabilir. Her çocuk gibi serebral palsili olan çocukların da oyuna olan gereksinimleri göz ardı edilmemelidir. Aksi halde devamlı

\footnotetext{
- İletişim adresi: Doç. Dr. Ünsal Tazegül, Iğdır Üniversitesi, Beden Eğitimi ve Spor Yüksekokulu, Iğdır, Türkiye

Tel: 0535 - 4357756 e-posta: unsaltazegul@gmail.com

- Geliș tarihi: 28 Șubat $2021 \quad$ Kabul tarihi: 14 Mart 2021
}

ORCID iD: Ünsal Tazegül, 0000-0001-9772-9305 • Özdemir Atar, 0000-0001-7941-2865 • Merve Ferah Tazegül, 0000-0002-2382-039X 
terapi ve rehabilitasyona giden çocuk sosyal yaşamdan kopabilmektedir. Bu durumun olmaması için veya en aza indirilmesi için tedavi edici etkisi olan hidroterapik yöntemler (su içi oyunlar, su içi aktiviteler gibi) veya yüzme egzersizlerinden yararlanılabilir. Çünkü oyun ve yüzme serebral palsili bireylerin fizyoterapi seanslarına gitmesi kadar önem arz etmektedir. Ülkemizde ise bu konunun önemi giderek artmaktadır. ${ }^{[5]}$

Egzersizin, serebral palsi üzerinde olumlu etkileri vardır. Çünkü ana sebep, kas kontrol ve postür (duruş) bozukluğudur. Durum böyle olduğundan, düzenli spor faaliyetlerinde en olumlu sonuçlar direkt (doğrudan) gözle görülür şekilde ortaya çıkar. Egzersiz, kas gruplarının güçlenmesine ve esnekliğinin artmasına yardımcı olur. Bu da serebral palsili bireylerin işini büyük ölçüde kolaylaştırır. Sporla, kas gruplarına ulaşan oksijen miktarı artar, bu da lif sayısının artmasına ve kas grubunun büyümesine, güçlenmesine ayrıca hareket nedeniyle daha esnek hale gelmesine sebep olur. Serebral palsili bireylerin gereksinimi olan şey tam da budur. Özellikle suda yapılan egzersizler, normal egzersizlerden çok daha etkilidir. Çünkü harcanan efor suda çok daha fazladır. Su bir direnç uygular ve egzersiz bu dirence karşı yapıldığından kas grupları daha fazla efor harcar. Böylece istenilen, fazlasıyla elde edilmiş olur. Spor, serebral palsili bireylerin egzersiz programlarına ek olarak uygulanan destekleyici ve alternatif tedavi yöntemidir. Serebral palsili bireylerde spor branşlarının etkilerini inceleyen çalışmalar sınırlı sayıdadır. Spor programları ile serebral palsili bireylerin motor işlev kısıtlılıklarını azaltmada ve işlevselliği artırmada daha hızlı yol almak mümkün olabilir. Serebral palsili bireylerde fiziksel aktivite ve hareketlilik seviyesinin belli bir düzeyde tutulması önemlidir. Çünkü serebral palsili bireylerde var olan bozukluklar, bu bireylerin günlük yaşam becerilerini ve fiziksel aktivite düzeylerini olumsuz etkileyebilmektedir. ${ }^{\left[{ }^{[]}\right.}$

Çocukluk döneminde uygulanan jimnastik eğitiminin, çocukların temel motorik özellikleri üzerinde olumlu etkisi olduğu bilinmektedir. Ayrıca jimnastik, çocukların vücut, kas, kemik ile eklemlerin işlevlerini yerine getirmelerinde çok iyi imkânlar verir, gerekli anatomik ve psikolojik yeteneklerin kazandırılmasında aracı olur. ${ }^{[6]}$ Jimnastiğin çocuklar için en önemli yararı, motor ve fiziksel gelişim üzerindeki olumlu etkisidir. Jimnastik esnasında yapılan koşuların, zıplamaların ve jimnastik aletleri üzerinde yapılan çeşitli hareketlerin çocukların kas-iskelet sistemi üzerinde ve kalp-solunum sistemi üzerinde olumlu etkileri olmaktadır. ${ }^{[7]}$ Zülkadiroğlu, 5-6 yaş grubundaki çocuklarda 12 haftalık yüzme ve jimnastik egzersizlerinin kondisyonel ve esneklik üzerine olan etkisini araştırmıştır. ${ }^{[8]}$ Araştırmanın sonunda, egzersiz uygulamasının çocukların esneklik ve temel motorik özellikleri üzerinde olumlu etkisi olduğunu bulmuştur. Kayapınar "Okul Öncesi Dönemde Uygulanan Hareket Eğitimi Programının Çocukların Fiziksel Özelliklerine Etkisi" başlıklı çalışmasında 5-7 yaş grubu anaokulu çocuklarında, okul öncesi dönemde düzenli olarak yapılan hareket eğitimi programının, fiziksel özellikler üzerindeki etkisini araştırmış ve hareket eğitimi programının fiziksel özellikleri olumlu yönde etkilediğini saptamıştır. ${ }^{[9]}$ Genel olarak fiziksel aktivitenin, solunum, dolaşım, kas-iskelet sistemi ve organizmaya ait diğer fizyolojik özellikler üzerine olumlu etkilerinin olduğu bilinmektedir. ${ }^{[10]}$

Abakay, serebral palsili çocuklarda, treadmill egzersizinin fiziksel ve bazı biyokimyasal parametrelere etkisini araştırmak amacı ile yaptığı çalışmasında, deney ve kontrol grubunun sistolik ve diastolik kan basıncı değerleri arasında anlamlı bir fark bulmuştur. ${ }^{[11]}$

Yılmaz'ın eğitilebilir zihinsel engelli öğrencilerle yapılan beden eğitimi ve spor derslerinin biyomotorik özellikleri üzerine etkisini incelediği araştırmasında 10-12 yaş aralığında, 40 gönüllü öğrenci yer almıştır. Gönüllü öğrencilerin yarısı beden eğitimi dersi alırken, diğer yarısı dersi almamıştır. Beden eğitimi dersine katılan ve katılmayan grupların ön ve son test değerleri arasında anlamlı fark saptanmıştır. Gruplar arasında ise, son test ölçümünde anlamlı fark bulunmuştur. ${ }^{[12]}$

Verschuren ve ark.'nın serebral palsili çocuk ve ergenler üzerinde, sekiz aylık aerobik ve anaerobik kapasiteye yönelik standartlaştırılmış egzersizlerden oluşan programın etkilerini değerlendirdikleri çalışmada, 34'ü egzersiz grubunda, 34'ü kontrol grubunda olmak üzere 68 çocuk ve ergen yer almıştır. Çalışmada, katılımcılara çeviklik testi uygulanmıştır. Sekiz aylık çalışma sonucunda egzersiz yapan grubun değerlerinde düşüş görülürken, kontrol grubunda artış gözlemlenmiştir. Gruplar arasında da $\mathrm{p}<0,01$ düzeyinde anlamlı farklılık bulunmuştur. ${ }^{[13]}$

\section{Egzersizin Serebral Palsili Bireylere Katkısı}

- Fitness (bedenen formda olma) düzeyi ve uyumunda artış

- Vücut imajı ve vücut kontrolünde artış

- Hareket kapasitesinin artması ile birlikte özgüven seviyesinin artması

- Motorik özelliklerde (koordinasyon, dayanıklııı, esneklik, denge vb.) artış

- Kas kaybının (atrofi) önlenmesi ve eklem hareketliliğinin artırılması

- İnaktif yaşamdan aktif yaşama geçilmesi

- Günlük yaşam aktivitelerinde artış, aktivitenin uzun süre devam ettirilebilmesi 
- Öz benlik ve rekabetçi duygu kazanma

- Sosyal yaşama katılma

- Bağımsız yaşam

- Aerobik dayanıklılık ve kardiyorespiratuvar fonksiyonda artış olarak söylenebilir. ${ }^{[5]}$

Serebral palsili çocukların yaşadıkları en büyük sorunlardan biri, gövde kontrollerinin yeterli düzeyde olmamasıdır. Bu durum; yürüme, uzanma ve oturma gibi aktiviteleri etkiler. Bu sebeplerden dolayı serebral palsili çocuklar günlük yaşamlarında birçok sorun ile karşılaşırlar. ${ }^{[14]}$ Serebral palsili çocukların gövde kontrolünün tipik gelişmekte olan çocuklara göre daha az geliştiği bilinmektedir. ${ }^{[1]}$ Postüral kontrol işlev bozukluğu, postüral ağlarda eksikliklere neden olan, birincil beyin hasarından kaynaklanmaktadır. ${ }^{[1]}$

Serebral palsili çocuklarda postüral denge kontrolü, normal gelişim gösteren çocuklarla karşılaştırıldığında daha kötüdür. Bunun sebebi, nöral motor kontrol mekanizmalarının yavaş ve bozulmuş gelişimi nedeniyle oluşan kas-iskelet sistemi anormallikleridir. ${ }^{[15]}$

Üç temel ayakta durma stratejisi vardır. Bunlar; ayak bileği stratejisi, kalça stratejisi ve adımlama stratejisidir. Bu koordinasyon kalıpları kazanılmış öğrenme yoluyla geliştirilir ve 7-10 yaşları arasında tamamen öğrenilmiş olur. Ancak serebral palsili çocuklarda, bu stratejiler bozulmuştur ve çocuklar postüral dengelerini sağlayabilmek için kendilerine özel biçimler geliştirerek dengelerini sağlamaya çalışırlar. Hemiparetik serebral palsili çocuklarda primer anormalliklerden biri, gastroknemius kasının spastisitesi sonucu gelişen ayaktaki ekin deformitesidir. Bozulmuş merkezi nörolojinin doğrudan bir sonucu olarak ortaya çıkar. Hemiparetik serebral palsili çocuk, bu disfonksiyonu telafi etmek için kalçayı normalden daha fazla fleksiyona alarak yürümeye başlar. ${ }^{[2]}$

\section{SEREBRAL PALSILI BIREYLERDE UYGULANAN EGZERSIZ MODELLERi}

Çok fazla klinik duruma sahip serebral palside, erken teşhis ve erken tedavi serebral palsili çocukların rehabilitasyon programında önemli bir yere sahiptir. Serebral palsili çocuğun yaşamını etkileyen en büyük problemin fiziksel uygunluk yetersizliği olduğu belirtilmiştir. ${ }^{[16]}$ Serebral palsili bireylere farklı türde rehabilitasyon amaçlı egzersiz modelleri uygulanmaktadır. Bu durum bireylerin fiziksel özellikleri ve vücut tutulumlarına göre farklılık göstermektedir.

\section{Yüzme ve Su İçi Terapi}

Yüzme ve su içi egzersiz programları, engelli bireyler için tavsiye edilmektedir. Özellikle su içi egzersiz programlarının serebral palsili bireyler için önemli olduğu bilinmektedir. ${ }^{[17,18]}$ Aynı zamanda su içi egzersizlerinin birçok avantajı olduğu da bildirilmiştir. ${ }^{[19]}$ Nöromusküler sistem yerçekimine karşı koyamasa bile su içi egzersizlerde, suyun kaldırma kuvveti, hareketin başlamasını tetiklemektedir. Artmış su viskozitesi vücudun bu zorlu aktiviteleri yapmasına izin verir. Suyun sıcaklığı önemli bir etkendir. Çünkü ısı iletimi suda havadan daha hızı ıerçekleşir. Özellikle $32^{\circ} \mathrm{C}$ 'lik bir su sıcaklığı spastisiteyi azaltır ve istem dışı yapılan hareketlerin azalmasına neden olur. Hidrostatik basınç eksteroreseptör ve proprioseptör stimülasyonunun artmasına yol açarak, akciğer ve solunum kaslarında artmış bir basınç yaratır. ${ }^{[17,20]}$ Ayrıca koordinasyon, nefes alıp verme veya konuşma gibi bazı fonksiyonlarda düzelme görülmektedir. ${ }^{[17]}$ Bunun yanı sıra, suyun kaldırma kuvveti yerçekimi etkisini ortadan kaldırarak postüral destek artışı sağlar. Bu yüzden serebral palsili çocuklar suda karadan daha kolay hareket edebilirler. Hem suyun kaldırma kuvvetinin direnci hem de suyun viskozitesi bir çeşit kuvvetlendirme ve aerobik egzersiz şansı tanıyabilir. Bu egzersizler serebral palsili çocuklara daha geniş motor beceri şansı sağlamaktadır. Su içi egzersizler daha güvenli ortam sağladığı için diğer egzersizlere göre ekleme binen yükü azaltır. ${ }^{[18]}$ Suyun gravite (yoğunluk, kaldırma) etkisi kaslara yardımcı olarak serebral palsili veya ampute bireylere suyun içinde daha özgür hareket etmelerini sağlamaktadır. ${ }^{16]}$ Özellikle alanda yapılan çalışmalar değerlendirildiğinde sınırlı sayıdaki çalışmalar, su içi egzersiz programının serebral palsili bireylerde aerobik kapasite gelişimlerine katkı sağladığını ortaya koymaktadır. ${ }^{[21]}$ Serebral palsili çocuklar için aerobik kapasite artışını hedefleyen uzun yüzme, sığ suda küçük adımlama, büyük adımlama, hoplama, yerinde koşu ve itici koşu, tekme atma (örneğin, bir yerden tutunarak tekme atmak gibi) egzersizlerini içeren çeşitli su içi egzersizler kullanılır (Tablo 1). ${ }^{[18]}$

Çocuğun işlevsel durumuna göre güçlendirme egzersizleri, yürüme denge eğitimi gibi tedavi edici egzersizler su içi ortama uyarlanabilir. Su içi egzersizlere katılım duvardan destekle, bir köpük havuz makarnası (uzun ve esnek bir yüzdürme yardımcısı), yüzen tahtalar, yüzen halterler, can yeleği, simit veya suda fiziksel engelli bireylerle çalışma becerisine sahip başka bir kişi yardımı ile artırılabilir. ${ }^{[18]}$ Yüzme, herhangi bir su içi egzersiz programının parçası olması gereken en sık aktivitedir. Çünkü serebral palsili çocukların başkasının yardımı olmadan özgürce hareket edebilmesine olanak sağlar. ${ }^{[16]}$ Peganofff'23] yaptığı çalışmada, serebral palsili bir kişide sekiz haftada, haftada iki kez yaptıkları yüzme egzersizi sonucunda, benlik saygısı parametrelerinde, omuz 
Tablo 1. Serebral palsili çocuklarda su içi egzersizler ${ }^{[22]}$

Kickboard ya da çeşitli yüzme malzemeleri kullanarak yüzme

Sığ suda yürüyüşs (öne-arkaya-yana yürüme, kol salınımı ile ve dizi yükseğe kaldırarak adımlama)

Yüzdürme cihazı ile birlikte yavaş su koşusu

Suda dik durma (üst ve alt ekstremiteyi kullanarak dengeyi sağlama)

Yan tutamaçlardan tutunarak yüz üstü tekmeleme

Yan tutamaçlardan tutunarak zıplama

Yüzdürme cihazı ile sığ suda sıçrama ya da derin suda dizleri göğse çekme
Sığ ya da derin suda, bir yüzdürme cihazı ile kalça abduksiyon, adduksiyon

Bir yüzdürme cihazı ile derin suda makaslama (her iki alt ekstremite fleksiyon-ekstansiyon)

Top firlatma

Oturarak kol salınımları, göğüs rotasyonu, diz fleksiyon ve ekstansiyonları

Topu aşağı sıkıştırma

Çömelme ya da otur kalk egzersizleri fleksiyon ve abduksiyon eklem hareket genişliğinde artış olduğunu tespit ederken, Maniu ve ark. ${ }^{[17]}$ altı aylık su içi terapi programının yaşam kalitesine, fiziksel aktivite indeksine ve vital kapasite parametreleri üzerine olumlu etkisi olduğunu bildirmiştir. Yapılan farklı bir çalışmada ise Hutzler ve ark. ${ }^{[24]}$ 5-7 yaşlarında 46 serebral palsili çocukla yaptıkları çalışmada, altı aylık haftada iki kez yapılan yüzme egzersiz programının çocukların vital kapasitesinde artış sağladığını bulmuşlardır. Thorpe ve Reilly, 31 yaşında serebral palsili bir bireye 10 hafta boyunca, haftada bir kez su içinde yürüme, alt ekstremite direnç egzersizlerini içeren program uygulamış, alt ekstremite kaba motor fonksiyon skorunda, yürüme hızında, kas kuvvetinde, kendini algılama parametrelerinde iyileşme olduğunu bildirmişlerdir. ${ }^{[19]}$ Kelly ve Darrah'ın yaptıkları çalışmada ise serebral palsili çocuklara uygulanan su içi egzersiz programlarının; kaba motor işlev, yürüme, kas kuvveti, solunum işlevi ve esneklik üzerine pozitif etkilerinin olduğu belirtilmiştir. ${ }^{[18]} \mathrm{Bu}$ açıdan değerlendirildiğinde, yüzme ve su içi egzersiz modellerinin serebral palsili bireylerde olumlu sonuçlar yaratacağı ortaya çıkmaktadır.

\section{Serebral Palsili Bireylerde At Binme Egzersizi}

Engelli bireylerin çeşitli imkanları kullanarak yararlandıkları tıbbi tedavi ve terapi hizmetlerinin yanı sıra, alternatif tıp, tamamlayıcı tıp ya da bütünleyici tıp seçeneklerine yönlendikleri anlaşılmaktadır. Bu seçeneklerden bir tanesi de Türkiye'de "Hipoterapi" başta olmak üzere "At Destekli Terapi”, "Atlı Terapi”, "Terapötik Binicilik", "Uyarlanmış Binicilik", "At Destekli Terapi ve Öğrenme" ya da "Engelli Biniciliği” gibi çeşitli şekillerde isimlendirilen binicilik egzersizidir. ${ }^{[25]}$
Binicilik egzersizinin yararları arasında, çocukların sensorimotor deneyimlerini artırmak sayılabilir. Bu durumun kazanımları iki farklı şekilde görülmektedir. Birincisi, atın hareketlerine uyum sağlamak ve bu ritimde hareket etmek amacıyla yapılan pasif hareketlerdir (atın üzerinde düzgün oturabilmek, süratli kararda giderken kalkıp oturmak gibi). Bir diğer kazanım da attan bağımsız olarak değişken hedefleri içeren hareketlerdir (atın yönünü değiştirmek için dizgin yardımı kullanmak ve çalışma alanı içerisinde resim, rakam vs. içeren panolar, oyuncaklar gibi farklı nesneler kullanmak). ${ }^{[26]} \mathrm{Bu}$ faaliyetler çocukların temel motorik becerilerinin iyileşmesine ve istenmeyen kas hareketlerinin daha da pasif olmasına yardımcı olur. Burada asıl amaç ise çocukların aktif hareketlerini basitleştirmek ve ileri motor becerileri geliştirmeleri için değişik imkanlar oluşturmaktır. Bu şekilde terapötik at binme; devinimsel, uzay-konumsal ve vestibüler girdilerin iyileşmesini sağlar. Bu gelişme ise herhangi bir etkiye karşı verilecek, uygun cevapların verilmesinde önem taşır. ${ }^{[25]}$

Engelli bireylerin ilgilerini çekecek ve motivasyonlarını artıracak tedavi edici aktivitelerden olan binicilik egzersizinde, atın yürüyüşü esnasındaki sırt salınımları, kendine özel hareketleri, vücut sıcaklığı, konumu, insan vücudunun pek çok sistemini birden etkiler. Postüral cevapları kolaylaştırmak için uzman, çocuğu at üzerinde değişik şekillerde pozisyonlar. Duruş ve hareket işlevlerinin yanında; bilişsel, psikolojik, davranışsal ve iletişimsel gelişme oluşturulur. Eyersiz bir şekilde at binmek, insan vücuduna atın sıcaklığının direkt temas etmesini sağlar. Atın vücut sıcaklığı normalde insan sıcaklığından $1^{\circ} \mathrm{C}$ daha yüksektir. Bu durum çocukta gevşeme sağlar ve yüksek kas tonusunu azaltır. Alanda 
yapılan çalışmalar incelendiğinde Hipoterapi veya diğer binicilik egzersizlerinin, Serebral palsili çocuklarda postüral kontrol veya denge üzerinde olumlu etkilerini ortaya koymaktadır. ${ }^{[27]}$

Zadnikar ve Kastrin, çalışma sonuçlarının, terapötik binişlerin postüral kontrol ve dengeyi geliştirdiğini açıkça gösterdiğini ifade etmişlerdir. ${ }^{[27]}$ Bertoti ise çalışmasında, iyileşen işlevsel beceriler ile kas tonusu ve denge sağlamada klinik iyileşmenin kanıtlandığını, bu sonuçların tedavi edici at binmenin serebral palsili çocuklarda duruşu olumlu etkilediğini kaydetmiştir. Ayrıca bu çalışmasında, binicilik egzersizinin çocukların eklem hareketliliğinde, ağırlık aktarmalarında denge sağlamalarında ve kas kuvvetlerinde artış, kas gerginliklerinde ise azalma sağladığını belirtmiştir. ${ }^{[28]}$ Champagne ve ark., yaptıkları çalışmada, binicilik egzersizi sonrasında 4-12 yaş aralığındaki serebral palsili çocuklara uygulanan atlı terapi çalışmalarının motor beceriyi geliştirdiği sonucuna varmışlardır. ${ }^{[29]}$

\section{Serebral Palsili Bireylerde Bisiklet ve Koşu Bandı Eğitimi}

Serebral palsili çocuklarda kas tonusu zayıflığı ve düşük endürans durumlarında treadmill ve bisiklet eğitimleri uygulanabilir. Serebral palsili bireylerin rehabilitasyonunda bisiklet eğitimi önemli bir araç olarak kullanılmakla birlikte kardiyovasküler endüransı da olumlu yönde etkileyebilmektedir. Statik bisiklet ergometrelerinin kas kuvvetinde artışa sebep olduğu, yapılan araştırmalarla ortaya konmaktadır. Fakat araştırma metotlarında farklılıklar olduğu, şiddet, sıklık ve sürenin değişken olduğu görülmektedir. ${ }^{[30]}$

Kalistenik egzersiz formatında uygulanan koşu bandı eğitimlerinin ise son yıllarda serebral palsili çocukların tedavisindeki güncelliği artmıştır. Bu yöntemin araştırmalarda bireylerin yürüme hızını artırdığı ve kaba motor işlevlerini geliştirdiği ifade edilmektedir. ${ }^{[31]}$ Farklı bir araştırmada ise koşu bandı eğitiminin yürüyüşün spatiotemporal özelliklerini geliştirdiği belirtilmiştir. Yürümenin gelişimi serebral palsili çocuklarda hareketliliği artırmakta ve okul, ev ve toplum içerisindeki sosyal katılımı daha aktif hale getirmektedir. ${ }^{[33]}$ Koşu bandı eğitiminin kaba motor işlevlerin gelişiminde etkili olduğu ifade edilmektedir. Willoughby ve ark., yaptıkları çalışmada, koşu bandı eğitiminin kaba motor işlev ölçümü sonuçlarında, yürüme, koşma ve zıplama ölçütlerinde olumlu artışa neden olduğunu saptamışlardır. ${ }^{[32]}$

Bu açıdan değerlendirildiğinde egzersiz bisikletleri, günümüzde fiziksel aktiviteyi artırmak için sıkça önerilmektedir. Yapılan araştırmalar bisiklet egzersizinin özellikle de bireye uyarlandığında, fiziksel sağlığı geliştirmesinin yanı sıra duygusal iyi olma halini artırdığını da ortaya koymaktadır. Gerçek bisiklet egzersizinin yanı sıra, sanal bisiklet egzersizinin fiziksel sağlığa olumlu etkisi de bir çalışmayla gösterilmiştir. Bu çalışmaya göre eve dayalı sanal bisiklet egzersizi serebral palsili çocuklarda alt ekstremite kemik mineral yoğunluğunu artırmaktadır. Sanal bisikletin yanı sıra diğer sanal gerçeklik uygulamalarının da normal gelişen çocuklarda fiziksel aktiviteyi artırdığını gösteren çalışmalar mevcuttur. Serebral palsili bireylerde de sanal gerçeklik uygulanabilecek yöntemler arasında gösterilmektedir. ${ }^{[33]}$

\section{SONUÇ}

Serebral palsili bireylerde duruş, denge ve kas tonusunda farklı derecelerde sorunlar görülmektedir. Spor ve egzersiz ile bu sorunlar kısmen giderilerek bireyin yaşam kalitesi daha da artırılmaktadır. Yine sporun, serebral palsili bireylerde görülen solunum sorunlarının çözümüne etkisi olmaktadır. Solunum kaslarının gelişmesini sağlayarak bireylerin daha rahat solunum yapması sağlanmaktadır. Egzersiz, kas gruplarının güçlenmesine ve esnekliğinin artmasına yardımcı olur. Bu da serebral palsili bireylerin işini büyük ölçüde kolaylaştırır. Sporla, kas gruplarına ulaşan oksijen miktarı artar, bu da lif sayısının artmasına ve kas grubunun büyümesine, güçlenmesine ayrıca hareket nedeniyle daha esnek hale gelmesine olanak verir. Serebral palsili bireylerin gereksinimi olan şey tam da budur. Özellikle suda yapılan egzersizler, normal egzersizlerden çok daha etkilidir. Çünkü harcanan efor suda çok daha fazladır. Su, bir direnç uygular ve egzersiz bu dirence karşı yapıldığından kas grupları daha fazla efor harcar. Böylece istenilen fazlasıyla elde edilmiş olur. Su içerisinde yapılan egzersizlerin birçok yararı ve avantajı bulunmaktadır. Suyun kaldırma kuvveti sayesinde hareketlerin yapılması daha kolay olmaktadır. Yine binicilik egzersizleri, serebral palsili bireyler üzerinde olumlu etkiler yaratmaktadır. Binicilik egzersizleri özellikle serebral palsili bireylerin iletişim becerileri, sosyal ve zihinsel becerileri üzerinde olumlu etkiler yaratmaktadır.

Çocukluk döneminde uygulanan jimnastik eğitimi, çocukların temel motorik özelliklerinin gelişmesinde önemli bir yer tutmaktadır. Jimnastik çocukların; vücut, kas, kemik ve eklemlerin işlevlerinin istenilen düzeye getirilmesinde önemli bir rol oynamaktadır. Serebral palsili bireylerin yaşadıkları motorik sorunların çözümünde jimnastik önemli bir yer tutmaktadır.

Spor ve egzersiz serebral palsili bireylerin ayrıca ruhsal durumların da olumlu etkilemektedir. Oyun formatında yapılan spor aktiviteleri sayesinde serebral palsili bireyler eğlenmekte ve haz almaktadır. 


\section{KAYNAKLAR}

1. Güneş D. Serebral Palsili Çocuklarda Alt Ekstremite Selektif Kontrolü ve Gövde Kontrolünün Oturmadan Ayağa Kalkma Performansına Etkisinin İncelenmesi. Yayımlanmış Yüksek Lisans Tezi. İstanbul: Marmara Üniversitesi Sağlık Bilimleri Enstitüsü; 2020.

2. Güner B. Hemiparetik Serebral palsili Çocuklarda Üst Ekstremite Fonksiyonelliğinin Gövde Kontrolü, Denge ve Yürümeye Olan Etkisinin İncelenmesi. Yayımlanmış Yüksek Lisans Tezi. İstanbul: Aydın Üniversitesi, Lisansüstü Eğitim Enstitüsü; 2020.

3. Özcan H, editör. Cerebral Palsy, 1. Baskı. İstanbul: Boyut Yayın Grubu; 2005.

4. Papavasiliou AS. Management of motor problems in cerebral palsy: a critical update for the clinician. Eur J Paediatr Neurol 2009:13(5):387-96. Crossref

5. Atar Ö. Serebral Palsi ve Spor. İstanbul: Efe Akademi Yayınları; 2020.

6. Kesilmiş i. Dört-Altı Yaş Çocuklarda Jimnastik Antrenmanının Büyüme ve Biyomotor Yetiler Üzerine Etkisi. Yayımlanmış Yüksek Lisans Tezi. Mersin: Mersin Üniversitesi Eğitim Bilimleri Enstitüsü Beden Eğitimi ve Spor Ana Bilim Dalı; 2012.

7. Mülazımoğlu Ö. Bruninks-Oseretsky Motor Yeterlik Testinin Geçerlik, Güvenirlik Çalışması ve Beş-Altı Yaş Grubu Çocuklara Uygulanan Jimnastik Eğitim Programının Motor Gelişime Etkisinin İncelenmesi. Doktora Tezi. Ankara: Ankara Üniversitesi Fen Bilimleri Enstitüsü; 2006.

8. Zülkadiroğlu Z. Beş-Altı Yaş Grubu Kız ve Erkek Çocuklarda 12 Haftalık Jimnastik ve Yüzme Çalışmalarının Esneklik ve Kondisyonel Özellikleri Üzerine Étkisi. Yüksek Lisans Tezi (basılmamış). Adana: Çukurova Üniversitesi Sağlık Bilimleri Enstitüsü; 1995.

9. Kayapınar FÇ. Altı-Yedi Yaş Grubu Çocuklarda Hareket Eğitiminin Çift El-Göz Koordinasyonu ve Reaksiyon Sürelerine Etkisi. Yüksek Lisans Tezi. İstanbul: Marmara Üniversitesi Sağlık Bilimleri Enstitüsü; 2002.

10. Altınkök, T. Temel Motor Hareketlerin Geliştirilmesini içeren Özel Beden Eğitimi Program Tasarısının 5-6 Yaş Çocukların Temel Motor Hareketlerin Gelişimine Etkisinin Araştırılması. Yüksek Lisans Tezi. İstanbul: Marmara Üniversitesi Sağlık Bilimleri Enstitüsü; 2006.

11. Abakay H. Ambule Serebral Palsili Çocuklarda Treadmill Egzersizinin Fiziksel ve Bazı Biyokimyasal Parametrelere Etkisi. Yüksek Lisans Tezi. Kayseri: Erciyes Üniversitesi, Sağlık Bilimleri Enstitüsü; 2010.

12. Yılmaz H. Eğitilebilir Zihinsel Engelli Öğrencilerde Yapılan Beden Eğitimi ve Spor Derslerinin Biyomotorik Özellikleri Üzerine Etkisinin İncelenmesi. Yüksek Lisans Tezi. Isparta: Süleyman Demirel Üniversitesi, Sağlık Bilimleri Enstitüsü; 2012.

13. Verschuren O, Ketelaar M, Gorter JW, Helders PJM, Uiterwaal CSPM, Takken T. Exercise training program in children and adolescents with cerebral palsy: a randomized controlled trial. Arch Pediatr Adolesc Med 2007;161(11):1075-81. Crossref

14. de Graaf-Peters VB, Blauw-Hospers $\mathrm{CH}$, Dirks $\mathrm{T}$, Bakker $\mathrm{H}$, Bos AF, Hadders-Algra M. Development of postural control in typically developing children and children with cerebral palsy: Possibilities for intervention? Neurosci Biobehav Rev 2007;31(8):1191-200. Crossref

15. El-Shamy SM, Abd El Kafy EM. Effect of balance training on postural balance control and risk of fall in children with diplegic cerebral palsy. Disabil Rehabil 2014;36(14):117683. Crossref
16. Jorgic B, Dimitrijevic L, Lambeck J, Aleksandrovic M, Okicic T, Madic D. Effects of aquatic programs in children and adolescents with cerebral palsy: systematic review. Sport Sci 2012;5(2):49-56. https://www.sposci.com/PDFS/BR0502/ SVEE/04\%20CL\%2009\%20BJ.pdf

17. Maniu DA, Maniu EA, Benga I. Effects of an aquatic therapy program on vital capacity, quality of life and physical activity index in children with cerebral palsy. HVM Bioflux 2013;5(3):117-24. http://www.hvm.bioflux.com.ro/docs/2013.117-124.pdf

18. Kelly M, Darrah J. Aquatic exercise for children with cerebral palsy. Dev Med Child Neurol 2005;47(12):838-42. Crossref

19. Thorpe DE, Reilly M. The effect of an aquatic resistive exercise program on lower extremity strength, energy expenditure, functional mobility, balance and self-perception in an adult with cerebral palsy: a retrospective case report. J Aquat Phys Ther 2000;8(2):18-24.

20. Polat $S$, Kabakcı AG, İnce G, Yücel AH. Serebral Palside Tedavi Yöntemleri Olarak Yüzme ve Su İçi Terapi. Arşiv Kaynak Tarama Derg 2018;27(3):274-86. Crossref

21. Rogers A, Furler BL, Brinks S, Darrah J. A systematic review of the effectiveness of aerobic exercise interventions for children with cerebral palsy: an AACPDM evidence report. Dev Med Child Neurol 2008;50(11):808-14. Crossref

22. Brody LT, Geigle PR, editors. Aquatic Exercise for Rehabilitation and Training. United States of America: Human Kinetics; 2009. p.25-220.

23. Peganoff SA. The use of aquatics with cerebral palsied adolescents. Am J Occup Ther 1984;38(7):469-73. Crossref

24. Hutzler Y, Chacham A, Bergman U, Szeinberg A. Effects of a movement and swimming program on vital capacity and water orientation skills of children with cerebral palsy. Dev Med Child Neurol 1988;40:176-81. Crossref

25. Özcan K. At Binme Egzersizinin Serebral Palsili Hastaların Seçilmiş Motorik Özellikler Üzerine Etkisi. Kayseri: Erciyes Üniversitesi, Sağlık Bilimleri Enstitüsü, Beden Eğitimi ve Spor Ana Bilim Dalı; 2019.

26. Snider L, Korner-Bitensky N, Kammann C, Warner S, Saleh M. Horseback riding as therapy for children with cerebral palsy: is there evidence of its effectiveness? Phys Occup Ther Pediatr 2007;27(2):5-23. Crossref

27. Zadnikar M, Kastrin A. Effects of hippotherapy and therapeutic horseback riding on postural control or balance in children with cerebral palsy: a meta-analysis. Dev Med Child Neurol 2011;53(8):684-91. Crossref

28. Bertoti DB. Effect of Therapeutic Horseback Riding on Posture in Children with Cerebral Palsy. Phys Ther 1988;68(10):150512. https://pubmed.ncbi.nlm.nih.gov/3174832/

29. Champagne D, Corriveau H, Dugas C. Effect of hippotherapy on motor proficiency and function in children with cerebral palsy who walk. Phys Occup Ther Pediatr 2017;37(1):51-63. Crossref

30. Fowler E G, Knutson LM, DeMuth SK, Sugi M, Siebert K, Simms V, Azen SP, Winstein CJ. Pediatric endurance and limb strengthening for children with cerebral palsy (PEDALS) -a randomized controlled trial protocol for a stationary cycling intervention. BMC Pediatr 2007;7:14. Crossref

31. Damiano DL, Dejong SL. A systematic review of the effectiveness of treadmill training and body weight support in pediatric rehabilitation. J Neurol Phys Ther 2009;33(1):27-44. Crossref

32. Willoughby KL, Dodd KJ, Shields N. A systematic review of the effectiveness of treadmill training for children with cerebral palsy. Disabil Rehabil 2009;31(24):1971-9. Crossref

33. Özal C, Yazıcı M, Numanoğlu A, Günel MK. Serebral Palsili Bireylerde Fiziksel Aktivitenin Önemi. Ufkun Ötesi Bilim Derg 2010;10(1-2):37-50. https://dergipark.org.tr/tr/download/ article-file/762073 